The Canadian Journal of Higher Education, Vol. XXIII-2, 1993

La revue canadienne d'enseignement supérieur, Vol. XXIII-2, 1993

\title{
The Point of View of the Student in Attrition Research
}

\section{BRENT MCKEOWN*, ALLAN MACDONELL* \& CHARLES BOWMAN*}

\begin{abstract}
Until the early 1970's, research into attrition among postsecondary students was largely aimed at establishing correlations between the characteristics the students brought with them to an institution and dropping out. Virtually all of this research was unguided by any explicit theoretical framework. With the work of Spady $(1970 ; 1971)$, and that of Tinto (1975), a model was provided which became the theoretical foundation for most subsequent research into the problem. The model was based fundamentally on part of Durkheim's work on suicide, keying on the concept of integration. According to the model, those students who were integrated into the social and academic life of the institution were less likely to drop out, and the focus shifted to include not only "background" factors, but also the experiences of students after they were admitted to the institution. While creating the illusion of offering a clear theoretical framework, the key concepts of social and academic integration are only very loosely connected with the original Durkheimian idea. It is contended here that a firmer foundation for the development of an appropriate theoretical framework is more likely to arise out of a careful attempt to understand the actions of students in terms of the meanings things in their world have for them. Methodological techniques appropriate to this task are advocated, without denying the importance of many significant clues to be found in much of the current and past research in the field.
\end{abstract}

* Department of Sociology, University of New Brunswick. Fredericton, E3B 5A3. An earlier version of this paper was presented at the 1991 meeting of the Canadian Society for the Study of Higher Education. The paper has benefitted from the comments of three anonymous reviewers. 


\section{Résumé}

Jusqu'au début des années 70 , les recherches sur le décrochage scolaire au niveau postsecondaire visaient essentiellement à établir des corrélations entre le profil des étudiants à leur entrée dans l'institution et, d'autre part, leur décrochage. La presque totalité de ces recherches se faisait sans cadre théorique explicite. Les travaux de Spady $(1970 ; 1971)$ et de Tinto $(1975)$ crérent un modèle qui servit de fondement théorique à la plupart des recherches ultérieures sur ce problème. Ce modèle s'appuyait essentiellement sur une partie des travaux de Durkheim sur le suicide, particulièrement sur le concept d'intégration. Selon ce modèle, les étudiants intégrés à la vie sociale et intellectuelle de l'institution étaient moins susceptibles de décrochage. Il y eut dès lors un déplacement d'accent pour inclure non seulement les facteurs "généraux» mais aussi les diverses expériences des étudiants admis dans les institutions en question. Les concepts-clés d'intégration sociale et intellectuelle créent l'illusion d'un cadre théorique clair mais ne se rapportent que de façon lointaine à l'idée originale de Durkheim. Nous posons ici que l'on peut établir un point de départ plus sûr en étudiant attentivement les actions des étudiants en fonction du sens que revêtent les éléments de leur vie. Nous recommandons différerentes techniques méthodologiques adaptées à cette entreprise sans pour autant nier l'importance de nombreux indices importants que nous livrent les recherches actuelles ou passées dans ce domaine.

\section{Introduction}

While the evidence suggests that the dropout rate from postsecondary education in North America has remained at roughly the same level for many years (Tinto, 1982a; 1982b; Pascal \& Kanowich, 1979), a number of events have conspired to focus more attention on the matter and to generate more research. Increased enrolment pressure and funding constraints have drawn attention to the high costs involved (Gilbert, 1991; Smith, 1991; Gomme \& Gilbert, 1984). Some academic administrators, counsellors, residence staff, and others in frequent and direct contact with students have become more aware of the extent of attrition and have developed various impressionistic images of some of the complex factors involved (e.g., Stodt \& Klepper, 1987). Researchers in the field have scrutinized past research models and techniques, working to improve upon them (Bean, 1982; Pascarella \& Terenzini, 1979; Pantages \& Creedon, 1978).

The early efforts to develop a theoretical model to fill the apparent gap were seen to emerge from some of the ideas drawn from the classical work of 
Emile Durkheim on the subject of suicide. Durkheim argued that one of the reasons for suicide could be found in the extent to which people were not integrated into the social life of their communities. Deviant behaviour (in this case, suicide) was much more likely to result among those so isolated. Those working on the problem of student attrition thought that in this suggestion rested the germ of an idea that might help us better understand student dropouts. They felt that Durkheim has touched on a central aspect of the problem of social life that could be applied to persistence/withdrawal among university students. They postulated that those students who became firmly integrated into the social and academic life of the university would be less likely to become dropouts. It was on this intriguing foundation that the current dominant model employed by attrition researchers was developed and refined.

Most of those doing research in the field have, since the early 1970 's, used a particular model as the foundation for their research design. Almost all of them, including those who put the model together in the first place, have expressed concern over various limitations they have detected in this framework. In our opinion, many of the difficulties encountered by researchers can be traced to the fact that the interesting and useful ideas which lie at the heart of the model should be treated as loosely sensitizing concepts and not as a theory from which testable propositions may be usefully derived. Researchers have been placed in the position of "operationalizing" these concepts and defining key terms with virtually no help from the theory itself. In other words, while the key concepts have pointed vaguely at important elements in attrition, the useful findings have been much more a product of the creative imagination of scholars doing the work than of the theory itself.

The model is used ostensibly in a deductive manner, yet the hypotheses used in actual practice are at best loosely connected to the theory from which they are allegedly derived. It is our view that the main guiding force in the actual construction of testable hypotheses is the understanding that the researcher has of the empirical world of student life and not the theory. In practice, the process has been more one of induction than of deduction.

The idea that the operation was essentially deductive tended to keep researchers from delving deeply into the nature of university life and using the information so gathered to inform their research designs. They were forced, under the circumstances, to make educated guesses (some of them very good guesses it seems) about the nature of the empirical world under study. Since most of the researchers are drawn from the world of postsecondary education, they relied on the same kinds of impressions that are shared among many who 
have direct and frequent contact with students. The images undoubtedly contain some very accurate insights, but they are not based on a systematic and careful analysis of student life.

The quality of attrition research has improved significantly in recent years, in no small part as a result of the recognition by those doing the research that there may be something wrong with the model. It is upon that recognition, and these comments, that much of this argument rests. In the latter part of the paper we make some suggestions as to directions that might usefully be followed in the work of improving our understanding of attrition. These suggestions are based on, but not limited by, certain basic assumptions taken from early symbolic interactionism. We do not offer a new or alternative model for attrition research. At best, we offer suggestions as to the kinds of research which we believe could lead to the development of an improved model which might cast some light in one corner of the social world which we think has a bearing on the attrition process.

\section{The Tinto Model}

In a thorough review of the literature on attrition in 1970, William Spady argued that "beyond a few comfortable and familiar generalizations about the relationships between attrition and family background, ability, or academic performance, this literature lacks both theoretical and empirical coherence" (p. 64). It was his belief that a combination of Durkheimian theory, along with the use of "the more advanced multivariate statistical techniques and the standardized computer programs now available" would lead to a better understanding of the attrition process (p. 77, emphasis in the original).

Attrition researchers picked up on this criticism of earlier work, as well as on that part of Durkheim's work which seemed applicable. Spady's ideas, as modified by Tinto in 1975, were seen as a significant step forward from the days when "the vast majority of studies [had] searched for student or institutional variables significantly related to dropout behaviour with no conceptual model to guide or focus inquiry" (Pascarella \& Terenzini, 1980, p. 60).

What came to be known as the Tinto model allowed for a consideration of both "background factors" (such as high school performance, family background, ethnicity, etc.) and the institutional experience of students. Students entered university with certain characteristics, and those characteristics in turn were seen as having an influence on the extent to which the students were "integrated" into the system. Integration was seen as being of two sorts, social and academic. The university was seen as a "social system with its own values and 
social structure" (Tinto, 1975, p. 91). He argued that "lack of integration into the social system of the college will lead to low commitment to that social system and will increase the probability that individuals will decide to leave college and pursue alternative activities" (Tinto, 1975, p. 92).

There are four very appealing aspects to this model as originally presented. In the first place, there is no denial of the importance of the "background factors" which had been the centre of most of the earlier research. By building these variables into his model, Tinto was able in his synthesis to make use of virtually all of the best work done to that point. A second reason for the appeal of the model was its apparent foundation in the mainstream of classical theory. Thirdly, it focused attention on the experience students had in the institution, thus lending weight to the argument that the institutions could have an important effect on the attrition rate. Finally, it provided researchers with a sense of direction in their search for relevant measurable variables. A careful consideration of these four factors provides the foundation for some constructive criticism.

When we examine the work of Durkheim, we find virtually no clues as to how the appropriate "background variables" might be identified. The theory provides no boundaries nor rules for variable selection, and once selected there is no way of knowing their relative importance - at least not in Durkheim. The choosing and weighting of such variables is a product not of the classical foundation, but of the imagination, sensitivity, and design skill of the researcher. That part of the model, then, is just as open to wandering variable selection as was the pre-Tinto attrition research. This earlier approach Tinto described as no more than a "simple comparison of the rates of dropout among individuals of differing ability and social status characteristics" (Tinto, 1975, p. 90). The background variables are simply those that are widely thought to affect behaviour, with or without the thoughts of Durkheim. This was tempered, of course, by whatever sensitive impressions about student life the researcher may have gathered from working with students and from the examination of earlier research work.

The sophisticated effort by Pascarella and Terenzini (1980) to examine more carefully the importance of social and academic integration includes, and controls for, a wide range of these "background variables". It is instructive to see how these variables were selected. The authors state that these variables are chosen because they were "suggested as potentially important correlates of persistence/dropout behaviour by various critical reviews of attrition research" (p. 63). It is interesting to note that all of the research which was reviewed was 
published before the Tinto version of the model came out in 1975. There is no suggestion here that these variables may not be very important in attrition; but they do not seem to come out of the theory. One assumes they were chosen because they were seen as being somehow related to social and academic integration, either through sensitive observation or the discovery of some level of statistical correlation.

Putting the problem of the selection of background variables aside, there is the important contention that regardless of background factors, the experience of the students after they begin their attendance at university is central to the model. As Darden and Kuhn (1985) have pointed out, a careful examination of the work of Durkheim shows that the linkage with the Tinto model is tenuous at best. They note that:

Durkheim's model described an entirely different phenomenon. It referred to people who were not integrated into life, who lacked significant human ties - people who were unmarried, childless, living with no religion or the wrong religion in a society lacking mechanisms for such people to establish ties. These people were not even marginal people for the most part, but unconnected people. (Darden \& Kuhn. 1985, p. 161.)

Tinto was well aware of the complexity of student life. By recognizing both academic and social integration, he clearly saw the possibility of various subcultural influences and potentially conflicting commitments. One of the difficulties in the model is most certainly a product of the dominant perspectives of the time. Seeing dropping out as largely a product of malintegration, he writes:

When one views the college as a social system with its own value and social structures, one can treat dropout from that social system in a manner analogous to that of suicide in the wider society (Spady, 1970). One can reasonably expect, then, that social conditions affecting dropout from the social system of the college would resemble those resulting in suicide in the wider society: namely, insufficient interactions with others in the college and insufficient congruency with the prevailing value patterns of the college collectivity. (Tinto, 1975, pp. 91-92.)

In the first place, there are serious questions about the extent to which the notion of integration used in Tinto is related to the way it was employed by Durkheim. Even if we assume a relationship, we are left with very real problems in determining into what the student is supposed to be integrated. Tinto identifies two domains into which the student will or will not be sufficiently 
integrated. Given the nature of the Tinto model, we cannot turn to Durkheim for a solution. We would argue that Tinto is quite correct in placing stress on the experience of the students. The fact is that the central concepts as employed in the model appear to be derived from neither Durkheim nor the direct experience of the students.

In many respects, this aspect of the model is just as subject to wandering variable selection as is that which deals with background variables. Little solace can be found in the notion that this model is deeply rooted in the mainstream of sociological theory. It is certainly related to certain key sensitizing concepts in sociology: the idea that our behaviour is profoundly affected by the nature of relationships we have with other people and the extent to which we share certain values. Aitken (1982) sums up the model by telling us that the "struciural or theoretical model is based on the premise that a student's decision to remain at a specific university or college is directly determined by major aspects of the student's experience (along with the possible intervention of major external factors)" (p. 33). While not agreeing with the deterministic tone of this statement, we would agree that the model does touch, however vaguely, on what must be important. The extent to which this model works (and within limits it does), is a product of the insight and intuition of Tinto and other researchers, not of Durkheim.

Those who work directly with students know from experience that the reasons for dropping out must involve more than just the rather mechanical notion that students with certain background characteristics would be more likely to drop out than others. They could see that from working with students. The kinds of experiences the students had after they arrived had to be important. Long before this model was introduced, efforts had been made by postsecondary institutions to encourage "fitting in". By making social and academic integration the key elements in his model, Tinto emphasised the idea that rates of attrition were significantly influenced by events which took place after students came to the university. This implied that there was much more that these institutions could do to reduce attrition. He did, however, recognize that there are important limits on the degree of institutional control, and certain dangers inherent in any effort to exercise that control (Tinto, 1982a; 1982b).

The centrality of the student experience suggests that a special effort should be made to get a much better understanding of the nature of that experience. However, instead of starting with an exploration of that experience, effort was directed to the derivation, or more accurately the construction, of testable hypotheses, allegedly from the model. Instead of beginning with an effort to 
discover what was of importance to students, those things were assumed. Matters of potentially critical importance in determining the connection of the student to the social and academic life of the institution were taken for granted.

The idea that there was a reasonably firm theoretical foundation tended to be self-confirming. By thinking about what might be important to students, and by making some sensitive guesses, the researchers came up with testable propositions. When there was some statistical confirmation of the view that student experiences were important, this was taken as confirmation, at least in part, of the theory. The truth was that the researchers had confirmed, in a limited way, the accuracy of some of their own insightful guesses. This is the element which tended to fix the model in a central location in attrition research. It is very difficult to argue with success. As Darden and Kuhn point out, "the model works in comparison to research done with no theoretical model" (1985, p. 162). They also argue that the model is, in some ways, correct. In our view it is correct in that it draws attention particularly to the experience of the student while acknowledging the importance of background factors.

This model works, in part, because it is remarkably plastic. It allows the inclusion or exclusion of variables in a strikingly free fashion. Even when the statistical evidence gathered suggests that key variables may operate in ways quite opposite to that predicted by the model, its flexibility allows adjustments without serious disruption to the overall theoretical framework. Several studies of commuter institutions illustrate the ease with which plausible accounts within the parameters of the model may be offered for what initially appear as statistical contradictions (Dietsche, 1990; Stewart, 1990; Pascarella \& Chapman, 1983; Pascarella, Duby \& Iverson, 1983). As long as the factors can somehow be related to the vague categories of "background" or "integration" they can be placed in the model. Normally, a tight explanatory model can be rejected because it cannot deal with certain aspects of a problem. Some of the more recent concerns over limits to the model expressed in the literature have highlighted this issue.

Gilbert and Auger (1987), in their consideration of the limitations of previous research, conclude that section of their paper by noting:

Finally, and perhaps most importantly, the existing theoretical model of attrition has tended to be a closed causal system. Other possible explanatory variables such as reasons, the role of finances, employment alternatives, have not been incorporated into the model. (pp. 10-11.) 
The history of the model's use has been characterized by the addition of variables (e.g.. Stage, 1989; Bean, 1985). Tinto himself warned against the dangers of this process: "attempts to greatly increase a model's explanation of variance - for instance, through the inclusion of a large number of variables often result in comparable loss in clarity of explanation" (Tinto, 1982a, p. 688).

Recent concems expressed by users of the model tend to put it back into the much more modest position it deserves, and one which is more consistent with the claims of Tinto. Tinto and Spady had the wisdom to recognize that the kinds of relationships students established at university, along with the extent to which they adopted certain values, had a part to play in the decision to stay or leave. This is an important idea, and the evidence we have lends support to it. Refinement of that good idea can come out of a careful examination of the world in which students live, in order better to understand the values which compete for their attention and the problems and nature of student relationships (Bean, 1985). Many interesting efforts have been made to refine. define, clarify, and elaborate these ideas, but these efforts have remained at some distance from that corner of the social world they wish to explain. In an effort to understand how this has happened, and how it might be corrected, we turn to a consideration of certain assumptions about the way social life seems to work on a day-to-day basis.

\section{An Interactionist Critique}

While other models have been presented since 1975 (e.g., Bean, 1982; Price. 1977), the Tinto framework has retained its dominance in attrition research. The use of an interactionist perspective as a basis for constructive criticism has been rare, and largely ignored. In 1985, Darden and Kuhn provided a useful critique of the Tinto model in which they raised serious questions about the link between Durkheim and the model. They accepted the idea of integration as important, but looked at it from another point of view:

Looking at these factors from a symbolic interactionist view, we can see that it is the interaction between the student's definitions and expectations and those of significant others which shapes the context of the decision to attend college or not, and to dropout, to stopout, or stay. (Darden \& Kuhn, 1985, p. 162.)

The methodological approach taken in that paper is, however, somewhat inconsistent with the theoretical principles advocated. Attinasi (1989), recognizing some of the weaknesses in the integration model, agreed that these guiding 
ideas had added to the fruitfulness of attrition research. In looking at the history of this research he notes that:

As the preoccupation with the identification of correlates has been replaced by an interest in explaining the processes that lead to persistence and withdrawal behaviors, the models have held out the possibility of reaching an understanding of the underlying dynamics of persistence/attrition phenomena. Still, none of the available models has proved more than very modestly successful in explicating those dynamics. This is the result, in the author's judgment, of certain conceptual and methodological shortcomings shared by the existing models. (Attinasi, 1989, p. 250.)

Attinasi (1989, p. 251) points out that the study he did was "guided only by a broad research perspective - the sociology of everyday life". By this he meant that he was employing the general assumptions of symbolic interactionism and ethnomethodology. Unlike the Darden and Kuhn work, Attinasi"s small exploratory study of attrition among Mexican American students was much more consistent methodologically with the interactionist perspective and raises very interesting questions about the nature of social integration. Attinasi argues that "the extent to which social integration influences persistence is not the extent to which it promotes the individual's moral conformity to the institution" (p. 270). He contends that his data show that the importance of social integration is much more pragmatic, in that the main importance of social relationships at the college has to do with helping the student to deal with the practical problems of living and working in that particular environment. Given the limited nature of the study, it is impossible to know just what social integration means to students in a more general way. The study does suggest that we know very little about the values, relationships, and practical problems that students face every day. or how they make decisions.

There is not heavy theoretical weight behind Attinasi's study. He, like Tinto and Spady before him, picked up on a good idea from the body of sociological literature. Without denying the potential importance of integration as a concept, he emphasised the notion that a concentration on the point of view of the actors would be very instructive.

Symbolic interactionism is a broad label which includes a variety of sometimes conflicting ideas. There are difficulties with the handling of social structure and the like. Methodologically, there are a wide range of problems. Furthermore, the current mixing of ethnomethodology, phenomenology and symbolic interactionism has blurred lines and created new languages in social 
analysis. But in our view, a consideration of a few traditional interactionist ideas will prove useful in clarifying some problems in attrition research and in pointing the way to research possibilities which may help to alleviate some of these difficulties.

Long before the Tinto model was published. Herbert Blumer commented on the way in which variables like "social integration" were commonly used in social science:

[One] kind of generic variable in current use in our discipline is represented by unquestionably abstract sociological categories, such as...social integration.... In actual use they do not turn out to be the generic variables that their labels would suggest. The difficulty is that such terms...have no fixed or uniform indicators. Instead, indicators are constructed to fit the particular problem on which one is working. Thus, certain features are chosen to represent the social integration of cities, but other features are used to represent the social integration of boys' gangs....It seems clear that the indicators are tailored and used to meet the peculiar character of the local problem under study. (Blumer, 1969. p. 129.)

Social integration as used in the attrition model is not a generic variable. The ideas of social integration and academic integration have clearly been "tailored and used to meet the peculiar character" of the problem of attrition.

At the heart of the interactionist perspective is the idea that human beings act toward things in this world in terms of the meaning those things have for them. These meanings arise out of interaction with other people (Blumer, 1969, p. 2). This is not to suggest that the structure. rules and practices of the university, the backgrounds of the students, grade point averages, social relationships and the like are irrelevant. There are, of course, very real constraints imposed on all human beings, regardless of their meanings.

However, current attrition research typically begins with assumptions about the meanings held by students as they engage in working their ways through, around, and out of universities. They have been imposed on the world of the student instead of arising from a careful study of that world. In fairness it should be stated that most, if not all, attrition researchers are not foreigners to the academic world. It is safe to say, however, that rarely has attrition research been firmly grounded in the realities of student life.

Every student is, of course, unique. The decision to drop out is in part a product of the meanings students individually attach to the various experiences in their lives. This suggests that a good deal could be gained by starting with a 
much better sense of student life and the goals and priorities which prevail in that life.

For social scientists the search is for common patterns of shared meanings out of which general statements can be made about specific empirical situations. The best place to begin is not with educated guesses about what student life is like, and just what kinds of meanings are thought to be generally shared, but rather with seeing those meanings in context.

Understanding the actions of students and other players in the university should begin with an effort to grasp the meanings these elements have for them. Unless there is a grounding in that empirical world, all of the adding of variables, clarifying of operational definitions, and improving of statistical techniques are likely to be of limited value.

If we assume that some meanings remain constant over time, there is no reason that such a research effort may not place variable analysis in a more comfortable position. The most relevant variables could be more easily identified and the relationships among them more clearly recognized. The caution must be made, however, that meanings are not fixed. The way in which students regard universities and their place in them will change over time. It may be worth pointing out that we believe student life to be a very complex matter in which there are many different points of view. There is no suggestion here that there is a single shared set of beliefs among students. We do believe, however, that there are certain general patterns which could be identified.

\section{Some Ideas from the Literature}

Several of those who have made important contributions in attrition research have recognized that the point of view of the actor is a critical issue. In his original presentation of the model, Tinto wrote that:

...the model of dropout proposed here accepts, as central to the process, the notion that perceptions of reality have real effects on the observer, and for a variety of reasons, persons of varying characteristics may hold differing perceptions of apparently similar situations.... [I]t is the perceptions of the individual that are important. (Tinto, 1975, p. 98.)

The identification of the "perception of reality" as "central to the process" is clearly reflective of the Thomas dictum which holds that if a situation is defined as real, it is real in its consequences. Here is a clear statement of a principle which lies at the heart of the interactionist perspective. Since the principle of social integration already shifted attention to the experience of the student, 
this fundamental point appears to have been lost in the flow of research generated by the particular interpretation of the Durkheimian conceptions.

Some sensitive observers have, while using the model, demonstrated a degree of uneasiness with it (Pascarella \& Chapman, 1983). Gilbert and Auger (1987) made a point of identifying certain limits on it, based on their own work and that of others. They specifically mention differences between institutions, the difference between dropouts and transfers, the status of temporary withdrawal, and the difficulties of sorting out the interaction among various causal factors. In addition to these specific definitional and analytical problems, they also noted that "little information is obtained directly from those altering their attendance status to ascertain actual reasons for doing so" (Gilbert \& Auger, 1987, p. 1). This observation indicates one direction which future research might profitably take.

While most of the research into attrition does not deal directly with student points of view except in the form of responses to structured questionnaires, there are some findings in this and other areas which are instructive. The Dalhousie University study of student attrition makes it very clear that student life is a highly complex matter. The study showed that students made friends, but it also made it clear that most of this had little to do with formal extra-curricular activities provided by the university. The authors state that "social integration appears to have occurred through informal social networks" (Day, Murphy, \& Marriott, 1987, p. 7). This important observation raises questions about what "integration into the university community" might mean, leaving open the question of just what the students are integrated into.

It would be interesting to know something more about the "informal social networks" in which students are involved. Tinto (1988) considers the rites of passage through which students may go and points out: "Despite the mass of quantitative evidence on reasons for student departure, we do not fully understand, for example, how students perceive their own departure at varying points during their college career" (p. 451). What are the goals, values, and priorities of these students? How are these elements related to academic achievement and attrition? Like other thoughtful pieces of work in the field of attrition, this study is highly suggestive of directions for the future.

While generally seen as lying outside of the field of attrition research, there are some studies which provide insight into student life. Moffat's (1989) largely ethnographic and atheoretical study of student life at Rutgers University may provide us with some idea of the kind of social networks into which students become integrated. and raises important questions about the extent to which 
those networks are related to the academic value system as referred to in the integration model.

In discussing academic practices, Moffat comments on some of the value orientations he detected and makes reference to work done on the same subject years before:

Three sociologists have written an excellent ethnography of the grading process at the University of Kansas based on research in the late 1950s that proves that the pragmatics of "making the grade" came first for almost all the students and that substantive intellectual understandings of the material they were learning came a distant, optional second (Becker, Geer, and Hughes, 1968). This mentality is undeniably a general one among American college students. as central to undergraduate academic routines at Rutgers in the 1980s as it was at the University of Kansas Iwenty-five years ago. The only puzzle is why three otherwise intelligent sociologists should have expected - given the institutional structure of modern American higher education, especially in its mass state-college version - that any other socially conditioned mentality might have dominated among the students. (Moffat, 1989. p. 287.)

While this is clearly a very large generalization about student value orientations, it suggests that whatever students are integrated into, it may be something very different from the image emerging from the model. The Dalhousie finding that the students are generally integrated into small informal social networks still leaves important questions about the relationship between these networks and the values of the institution in which many of them exist. The Moffat study, and the Attinasi exploratory work, lend at least some support to the idea that a much better understanding of student realities would contribute in important ways to our understanding of attrition. We are left then with the problem of identifying specific research and methodological techniques for the gathering of this kind of data.

\section{Some Methodological Questions}

Many universities are large both physically and numerically. Each has an organizational structure within which a wide range of players (students, staff, faculty, administrators, etc.) define situations, establish and change goals, become involved in social relationships, and make decisions. Of course most of these people establish close relationships with only a few of the other players. It must be kept in mind that these people live, in some sense, in the same objective 
reality and that they frequently share certain definitions about aspects of that reality. It is in this context that students make decisions (including the decision to drop out) and have them made for them (being required to withdraw might be an example).

When Gilbert and Auger (1987) wrote about the "actual reasons" for withdrawal, they recognized that such things as having few friends at the university or limited contact with faculty were not the "real reasons" for withdrawal. It is the meaning such relationships have which is important. Even something as apparently objective as a student's financial situation has to be seen in the light of meaning.

By way of an example, students withdrawing from our own Faculty of Arts are asked to discuss their reasons for doing so with someone in the Dean's office. On the forms used for withdrawal, the students are supposed to check off a box indicating just what the reason is. Such categories as "financial," "medical," "academic," and "other" are provided. It seems that for most students, most of the time, this final interview about withdrawal is just another little hurdle standing between them and getting out. Many do not even bother with it. The interview is aimed at seeing if there is some way in which the institution may be of assistance to students, particularly if they wish to remain.

On many occasions, while the "financial" box is checked off, it appears that the students do not like being at university, are performing badly, and would most certainly have left even if they won the lottery (perhaps especially if they won). It might well be that in some cases, financial difficulty is seen by the student as one of the more respectable reasons for leaving. This is not to suggest that many students are not hard pressed financially. Students do, however, stay under what seem to be terrible financial burdens, while others who leave for financial reasons are actually much better off in some objective sense.

It is interesting to note that Spady, when presenting his version of the model in 1970, was well aware of the tendency for students to provide answers to questions which did not reflect the "real reasons" for departure. For example, he noted that "in giving reasons for leaving college, dropouts tend to avoid the stigma of being a failure. In the face of more objective criteria. however, many of these explanations seem inadequate" (Spady, 1970, pp. $71 \mathrm{ff}$.).

In spite of this concern over the reliability of student responses, the great bulk of Spady's empirical work (and most of that of others in the field of attrition) relies on just those kinds of responses as the major sources of data. It is apparently assumed that such "distortions" of reality will be somehow discovered by reference to other "objective" data, such as the students" actual financial 
situation. The meaning that money, grades, and the like have for students is taken for granted. The researcher apparently knows the "real" meaning of such things. While lip-service is often paid to the importance of the point of view of the students, it has been pushed aside in the search for what are seen as more important factors. The same kind of argument can be made of other "objective" conditions like medical problems. All of this is mentioned just to lend weight to the Gilbert and Auger argument. The extent to which the translation of the model's key concepts into operational definitions and hypotheses captures the process of atrition must be questioned.

Attinasi, in commenting on the history of attrition research, contends that these "models have been developed on the basis of, and tested with, data collected from institutional records and/or by means of fixed-choice questionnaires. These are methods of data collection that effectively strip away the context surrounding the student's decision to persist or not to persist in college and exclude from consideration the student's own perceptions of the process" (Attinasi, 1989, p. 250). We must be careful to avoid the argument that institutional data and the information gathered from fixed-choice questionnaires cannot be very useful. That great caution must be exercised in the use and interpretation of such data. goes without saying. Whatever else they may be, things such as grade point averages can provide some fascinating clues about the student's relation to the institution. Factors like age, particularly when we see the generally higher academic performance of mature students, can provide intriguing clues about attrition. There is nothing inherently wrong with institutional and questionnaire data. provided that these data are treated as provisional indicators.

That this has not always been the case in attrition research is quite apparent. Questions about the interpretation of such data can easily be raised by anyone working directly with students. Academic counsellors are often in the situation of looking at transcripts and making judgments. The wise counsellor knows that the transcript showing a G.P.A. of $1.7 / 4$ could be that of a student who spends all of his or her waking hours arranging or attending parties; or it could also be the transcript of the mature single parent with two children and thirty hours a week of part-time work; or of the very intelligent student in nursing who spends all of her/his time reading Hegel. The use of these data, even those which appear to be most "objective", must be treated with immense care, a comment which applies equally to an examination of the relationships among such variables. 
There is what amounts to another order of data, and this is the type which is frequently found among the "endogamous" variables in attrition research. The best example has to do with measures of social integration. Reliance here is often placed on the responses to questions for which there may be a wide range of reasons for answers which do not capture what the researcher was after. In discussing his ethnographic work on student life at Rutgers, Moffat raises questions about certain methodological techniques:

Conventional accounts of American college students rely on the anecdotal knowledge their professors have of them - a dubious source - or on questionnaires or structured or unstructured interviews. Questionnaires usually require their subjects to respond to predetermined topics, however; with students, they are about what adult investigators have decided should be relevant to youths in advance. Interviews with adolescents, especially with glib college adolescents, also encourage subjects to talk in their most formal, adult-sounding ways. (Moffat, 1989, p. xv.)

Moffat used, among other techniques, participant observation in the residence system at Rutgers to gather some of the data he used. It is our view that while participant observation may well be one of the more productive ways of gathering some of the data we think is important, it is not the only way. His comments about the "glib" answers one might get from students raises an important issue in connection with the integration model.

Students, like other human beings, have at their disposal a set of "appropriate" answers which are used in particular contexts. These often reflect what is generally seen as desirable, rather than the actual priorities of the individual as revealed in behaviour. It is very difficult to know if a student who reports studying three hours a day is reporting what she does, or what she thinks is an appropriate response. If someone indicates that getting a degree is important, we have very few ways of knowing to what extent that is simply a handy response, and we certainly have no way of determining from that response how such expressions are related to the actual allocation of resources in the student's life. Participant observation does not guarantee that such rhetorical usages will not come into play. It does, however, give the observer other bits of information against which statements may be checked.

The rather easy dismissal of questionnaires and interviews in the Moffat work should be questioned, as should the rather two-dimensional image he presents of other institutional players. Granted, he is concentrating on the point of view of students, and perhaps students do see these other actors in just this way. 
His approach does raise questions about how we look at university life. Students make decisions of all kinds, including those which result in dropping out. Whether these are well-thought-out decisions or virtually automatic or whimsical decisions is an empirical question. The fact is. however, that they are made in the social context of the university. It is our view that students make these decisions in a highly dynamic context in which there are many players.

Much of the recent attrition research has emphasized the nature and quality of the relationships which exist (or do not exist) between faculty and students. The relationship between faculty and students is a dynamic multi-faceted process. Clearly the view that students have of faculty is related to the view that faculty have of students. They deal with one another in terms of what each is in the eyes of the other. Faculty lounges are full of stories of the ineptitude and duplicity of students, just as student lounges echo similar evaluations of faculty. Needless to say, it is not uncommon to hear positive evaluations as well. The point is that student opinions are not shaped independently of the views of faculty. There is a dynamic interplay here out of which emerges a variety of definitions. Examining student points of view without reference to the perspectives of other players is to create a somewhat artificial image. If the argument that closer student/faculty contact helps to reduce attrition has any validity, the dynamics of that contact are deserving of very close attention.

Attrition theorists are aware that the search for the perfect predictive model is in the realm of the quest for the Holy Grail. We know that there will probably never be a predictive model which deals with all of the complexity, contingencies, and idiosyncrasies of university life. There is no apparent reason. however, why we cannot do a better job of identifying the key factors which commonly lead to attrition. This will make use of the best methods at our disposal to get the kind of data upon which such frameworks can be built.

\section{Conclusion}

Some years ago, Jacqueline Wiseman produced a very useful work on the behaviour of skid-row alcoholics, entitled Stations of the Lost. In Blumer's foreword to that work, a number of principles are listed as providing guidance for that research, two of which are noted here:

The first of these is that any given sector of human group life must be seen as a diversified process in which the participants are fitting their respective lines of action to one another. ...Thus, group life in any given area is a moving process. ...[The second] principle is that to study human beings in any area of their social life it is necessary 
to view that area of life in terms of their experience and from their point of view. (Blumer, 1970, pp. xi-xii.).

The approach that Wiseman takes is to see the world of the actors in question as people with certain values and objectives, operating in a problematic world. They define and redefine situations and objects as they work in, around, and through that world. They make use of the material available to them, including their own attributes, certain shared definitions, and other resources, as they work out their lines of action on a day-to-day basis. It seems that university and college campuses are complex social locations, which have been thought about and studied often but which, in important ways, remain largely unexplored. In our judgment. the attempt to look at social life from the point of view of the actor is the beginning point in the process of building more adequate theories of human behaviour.

One need not adopt an interpretive perspective in order to recognize the serious limitations of the current uses of the attrition model. It is our view, however, that whatever theories emerge should be more firmly grounded in an examination of the worlds of the actors than is the current practice. One basic aspect of this approach, for example, is that the human studies should properly be truly empirical studies, in the fundamental sense that they start with a look at the real world, which is assumed to be the meanings and experiences of human actors. Thus, attempts to define sociological concepts definitively (and attempts to interrelate them in a priori or armchair theories) before a careful examination of the real, empirical world-as known and experienced by the actors-is seen to be premature. Theories should fit data, by arising inductively from the firm grounding of an examination of the empirical world-that is, again, from an examination of the actual. experiential worlds of the actors.

Thus, when Pascarella and Chapman (1983) suggest, for example, that "perhaps a major portion of persistence/withdrawal behavior is so idiosyncratic, in terms of external circumstances and personal propensities, that it is difficult to capture in any rational explanatory model" (p. 99), they seem to us to suggest that an examination of individual, personal experiences might be more instructive than disheartening. Indeed, a careful, comparative and inductive examination of the actual experiences of students and their perceptions of them should almost certainly prove to be productive of useful, as well as enlightening, theoretical understandings of attrition as a part of the larger picture of the student experience and of university life. The authors recommend that more research effort should be made to examine the life of the university and the people in it by employing techniques which are most likely to capture the 
meanings, goals, and priorities of the key actors, and to examine the techniques they actually use in working their ways in. around, and through the institutions of postsecondary education.

\section{References}

Aitken, N.D. (1982). College student performance, satisfaction and retention: Specification and estimation of a structural model. Journal of Higher Education,53, $32-50$.

Attinasi, L.C. (1989). Getting in: Mexican American's perceptions of university attendance and the implications for freshman year persistence. Journal of Higher Education, 60, 247-277.

Bean, J.P. (1982). Dropouts and turnover: The synthesis and test of a causal model of student attrition. Research in Higher Education, 12, 155-187.

Bean. J.P. (1985). Interaction effects based on class level in an explanatory model of college student dropout syndrome. American Educational Research Journal, 22, $35-64$.

Becker, H.S., Geer, G., \& Hughes, E.C. (1968). Making the grade: The academic side of college life. New York: John Wiley.

Blumer, H. (1969). Symbolic interactionism: Perspective and method. Englewood Cliffs, NJ: Prentice-Hall.

Blumer. H. (1970). Foreword. Pp. xi-xiv in J.P. Wiseman, Stations of the lost: The treatment of skid row alcoholics. Englewood Cliffs, NJ: Prentice-Hall.

Darden, D.K., \& Kuhn. P.H. (1985). College attendance, contextual dissonance and the Tinto model. Free Inquiry in Creative Sociology, 13 (2), 161-164.

Day, V., Murphy, J., \& Marrioth. E. (1987). Student attrition at Dalhousie: A report on the longitudinal cohort study conducted under the auspices of the committee on student attrition. Halifax: Dalhousie University

Dietsche, P.H.J. (1990). Freshman attrition in a college of applied arts and technology of Ontario. Canadian Journal of Higher Education, 20 (3), 65-84.

Gilbert, S. (1991). Attrition in Canadian universities. Report \# 1 prepared for the Commission of Inquiry on Canadian University Education. Ottawa: Association of Universities and Colleges of Canada.

Gilbert, S.N., \& Auger, M.S. (1987, June). Admission and attrition: Preliminary results of the CEASE project on student attrition. Paper presented at the Canadian Society for the Study of Higher Education, McMaster University, Hamilton.

Glaser, B.G., \& Strauss, A.L. (1973). The discovery of grounded theory: Strategies for qualitative research. Chicago: Aldine.

Gomme, I.M., \& Gilbert, S.N. (1984). Paying the cost: Some observations on the problem of postsecondary student attrition. Canadian Journal of Higher Education, 14 (3). $95-100$. 
Moffat, M. (1989). Coming of age in New Jersey: College and American culture. New Brunswick, NJ: Rutgers University Press.

Pantages, T.J., \& Creedon, C.F. (1978). Studies of college attrition: 1950-1975. Review of_Educational Research, 48, 49-101.

Pascal, C., \& Kanowich, S. (1979). Student withdrawals from Canadian universities: A study of studies. Toronto: Ontario Institute for Studies in Education.

Pascarella, E.T., \& Chapman. D.W. (1983). A multiinstitutional, path analytic validation of Tinto's model of college withdrawal. American Educational Research Journal, $20,87-102$.

Pascarella, E.T., Duby, P.B., \& Iverson. B.K. (1983). A test and reconceptualization of a theoretical model of college withdrawal in a commuter institution setting. Sociology of Education, 56, 88-100.

Pascarella. E.T., \& Terenzini. P.T. (1979). Interaction effects in Spady's and Tinto's conceptual models of college dropout. Sociology of Education, 52, 197-210.

Pascarella, E.T., \& Terenzini, P.T. (1980). Predicting freshman persistance and voluntary dropout decisions from a theoretical model. Journal of Higher Education, 51 , $60-75$.

Price. J.L. (1977). The study of turnover. Ames. Iowa: Iowa State University Press.

Smith, S.L. (1991). Report: Commission of Inquiry on Canadian University Education. Ottawa: Association of Universities and Colleges of Canada.

Spady, W. (1970). Dropouts from higher education: An interdisciplinary review and synthesis. Interchange, 1, 64-85.

Spady, W. (1971). Dropouts from higher education: Toward an empirical model. Interchange, 2, 38-62.

Stage, F.K. (1989). Motivation, academic and social integration, and the early dropout. American Educational Research Journal, 26, 385-402.

Stewart, M.J. (1990). Attrition from health professional schools in a Canadian university. Canadian Journal of Higher Education, 20 (3), 45-63.

Stodt, M.M., \& Klepper, W.M. (eds.). (1987). Increasing retention: Academic and student affairs administrators in partnership. San Francisco: Jossey-Bass.

Tinto, V. (1975). Dropout from higher education: A theoretical synthesis of recent research. Review of Educational Research, 45, 89-125.

Tinto, V. (1982a). Limits of theory and practice in student attrition. Journal of Higher Education, 53, 687-700.

Tinto, V. (1982b). Defining dropout: A matter of perspective. In E. Pascarella (ed.), New directions for institutional research: Studying student attrition (pp. 3-15). San Francisco: Jossey-Bass.

Tinto, V. (1988). Stages of student departure: Reflections on the longitudinal character of student leaving. Journal of Higher Education, 59, 438-455.

Ungar, S.B. (1980). The retention problem: An analysis of enrolment attrition at a Canadian college. Canadian Journal of Higher Education, 10 (1), 57-74. 